Check for updates

Cite this: Chem. Sci., 2018, 9, 6629

๑ All publication charges for this article have been paid for by the Royal Society of Chemistry

Received 8th June 2018

Accepted 5th July 2018

DOI: $10.1039 / \mathrm{c} 8 \mathrm{sc0} 02535 \mathrm{e}$

rsc.li/chemical-science

\title{
Acceleration of $\mathrm{CO}_{2}$ insertion into metal hydrides: ligand, Lewis acid, and solvent effects on reaction kinetics $\uparrow$
}

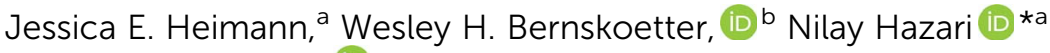 \\ and James M. Mayer (D) ${ }^{a}$
}

\begin{abstract}
The insertion of $\mathrm{CO}_{2}$ into metal hydrides and the microscopic reverse decarboxylation of metal formates are important elementary steps in catalytic cycles for both $\mathrm{CO}_{2}$ hydrogenation to formic acid and methanol as well as formic acid and methanol dehydrogenation. Here, we use rapid mixing stoppedflow techniques to study the kinetics and mechanism of $\mathrm{CO}_{2}$ insertion into transition metal hydrides. The investigation finds that the most effective method to accelerate the rate of $\mathrm{CO}_{2}$ insertion into a metal hydride can be dependent on the nature of the rate-determining transition state (TS). We demonstrate that for an innersphere $\mathrm{CO}_{2}$ insertion reaction, which is proposed to have a direct interaction between $\mathrm{CO}_{2}$ and the metal in the rate-determining TS, the rate of insertion increases as the ancillary ligand becomes more electron rich or less sterically bulky. There is, however, no rate enhancement from Lewis acids (LA). In comparison, we establish that for an outersphere $\mathrm{CO}_{2}$ insertion, proposed to proceed with no interaction between $\mathrm{CO}_{2}$ and the metal in the rate-determining TS, there is a dramatic LA effect. Furthermore, for both inner- and outersphere reactions, we show that there is a small solvent effect on the rate of $\mathrm{CO}_{2}$ insertion. Solvents that have higher acceptor numbers generally lead to faster $\mathrm{CO}_{2}$ insertion. Our results provide an experimental method to determine the pathway for $\mathrm{CO}_{2}$ insertion and offer guidance for rate enhancement in $\mathrm{CO}_{2}$ reduction catalysis.
\end{abstract}

\section{Introduction}

$\mathrm{CO}_{2}$ is an attractive feedstock for the sustainable synthesis of carbon-based commodity chemicals such as formic acid and methanol due to its abundance, low cost, and non-toxicity. ${ }^{1} \mathrm{~A}$ promising approach for the conversion of $\mathrm{CO}_{2}$ into these chemicals is the utilization of homogeneous transition metal catalysts. Recently, numerous molecular catalysts for $\mathrm{CO}_{2}$ reduction have been described, but further work is still required to develop practical systems. ${ }^{1}$ In many of these catalytic processes such as the hydrogenation of $\mathrm{CO}_{2}$ to formic acid or methanol, $\mathrm{CO}_{2}$ insertion into a metal hydride is proposed to be a key step. ${ }^{2}$ Similarly, in the dehydrogenation of methanol or formic acid to $\mathrm{CO}_{2}$ and $\mathrm{H}_{2},{ }^{1,3,3}$ it is postulated that the microscopic reverse reaction - the decarboxylation of a metal formate to generate a metal hydride and $\mathrm{CO}_{2}$ - is a crucial step. ${ }^{4}$ However, despite the importance of both these reactions in catalysis, there are few systematic experimental studies exploring these elementary reactions.

\footnotetext{
${ }^{a}$ Department of Chemistry, Yale University, P. O. Box 208107, New Haven, Connecticut, 06520,USA. E-mail: nilay.hazari@yale.edu

${ }^{b}$ Department of Chemistry, University of Missouri, Columbia, Missouri, 65211, USA

$\dagger$ Electronic supplementary information (ESI) available. See DOI: $10.1039 / \mathrm{c} 8 \mathrm{sc} 02535 \mathrm{e}$
}

One of the most common pathways for $\mathrm{CO}_{2}$ insertion into metal hydrides involves two steps: (i) nucleophilic attack of a metal hydride on the electrophilic $\mathrm{CO}_{2}$ to form an $\mathrm{H}$-bound formate and (ii) rearrangement of the $\mathrm{H}$-bound formate to generate the O-bound formate product (Scheme 1). ${ }^{2 b, 5}$ Reactions in which the first step is rate-determining are considered outersphere, as there is no direct interaction between the $\mathrm{CO}_{2}$ and the metal center in this transition state (TS), while reactions in which the second step is rate-determining are innersphere. ${ }^{5 a, b, e}$ An alternative concerted pathway involves a four-membered TS in which there is a direct interaction between $\mathrm{CO}_{2}$ and the metal center. ${ }^{5 a, e}$ This is also referred to as an innersphere pathway, as the TS for the concerted process most resembles the TS for the rearrangement of the H-bound formate in stepwise $\mathrm{CO}_{2}$ insertion. ${ }^{5 a, b, e}$ Information about the rate-determining TS for $\mathrm{CO}_{2}$ insertion into a given metal hydride is generally obtained from computational rather than experimental studies, as these reactions typically occur within seconds at room temperature, making the measurement of kinetics challenging. As a consequence, there are only a few isolated measurements of the rates of $\mathrm{CO}_{2}$ insertion into metal hydrides ${ }^{6}$ and little work comparing different metal systems or understanding the effects of the reaction environment. ${ }^{7,8}$ Furthermore, as part of studies on both catalytic $\mathrm{CO}_{2}$ hydrogenation and formic acid dehydrogenation, it has been shown that LA co-catalysts can dramatically increase 


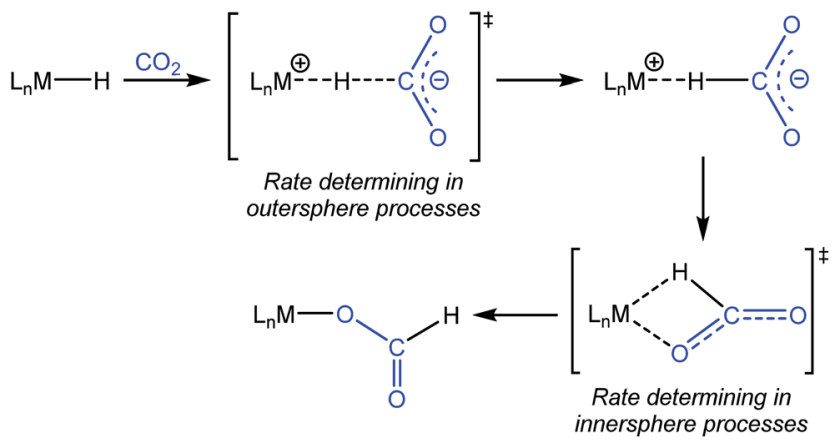

Scheme 1 Pathway for $\mathrm{CO}_{2}$ insertion into transition metal hydrides.

turnover number and turnover frequency. ${ }^{1,2 i, 4 c, 9}$ One explanation for the improved performance is that the LA assists in the insertion of $\mathrm{CO}_{2}$ into metal hydrides (or the decarboxylation of metal formates) by stabilizing the TS. ${ }^{4 c, \boldsymbol{d}}$ Although previous work has demonstrated that LAs can accelerate the rate of $\mathrm{CO}_{2}$ insertion into metal-alkyl bonds by stabilizing the $\mathrm{TS},{ }^{7 a-c}$ there is no quantitative evidence to substantiate this for metal hydrides. An improved understanding of these factors will facilitate the rational design of improved catalysts for reactions that involve either $\mathrm{CO}_{2}$ insertion into metal hydrides or the decarboxylation of metal formates.

Here, we use a stopped-flow instrument to measure the rates of $\mathrm{CO}_{2}$ insertion into transition metal hydrides. Specifically, we compare the role of solvent and LAs on reactions that are proposed to proceed via an inner- or outersphere ratedetermining TS. We show that LAs increase the rate of insertion for an outersphere system, but have no effect on the rate of $\mathrm{CO}_{2}$ insertion for an innersphere system. Furthermore, we explore the impact of systematically modifying the ligand scaffold on the rate of insertion for an innersphere system. We demonstrate that decreased steric congestion around the metal hydride and/or the addition of an electron-donating substituent in the ligand scaffold increase the rate of $\mathrm{CO}_{2}$ insertion. Our results also suggest that both inner- and outersphere systems exhibit similar solvent effects. This work represents the first quantitative study of LA effects on $\mathrm{CO}_{2}$ insertion into transition metal hydrides.

\section{Results and discussion}

\section{Solvent and Lewis acid effect for innersphere $\mathrm{CO}_{2}$ insertion}

To probe solvent and/or LA effects for an innersphere $\mathrm{CO}_{2}$ insertion reaction, the pincer-supported nickel hydride $\left({ }^{t \mathrm{Bu}} \mathrm{PCP}\right) \mathrm{NiH}\left({ }^{t \mathrm{Bu}} \mathrm{PCP}=2,6-\mathrm{C}_{6} \mathrm{H}_{3}\left(\mathrm{CH}_{2} \mathrm{P}^{t} \mathrm{Bu}_{2}\right)_{2}\right)$ (1) was synthesized using literature methods. ${ }^{10}$ Previous DFT calculations on a model system show that the rate-determining TS for $\mathrm{CO}_{2}$ insertion into $\mathbf{1}$ is a four-centered TS in which an oxygen atom from $\mathrm{CO}_{2}$ directly interacts with the nickel center. ${ }^{5 \boldsymbol{a}}$ Based on this, we regard $\mathbf{1}$ as a canonical example of systems that insert $\mathrm{CO}_{2}$ via an innersphere rate-determining TS. The kinetics of $\mathrm{CO}_{2}$ insertion into 1 to form $\left({ }^{t \mathrm{Bu}} \mathrm{PCP}\right) \mathrm{Ni}\{\mathrm{OC}(\mathrm{O}) \mathrm{H}\}\left(\mathbf{1}-\mathbf{C O}_{2}\right)$ were measured using a rapid mixing stopped-flow instrument with
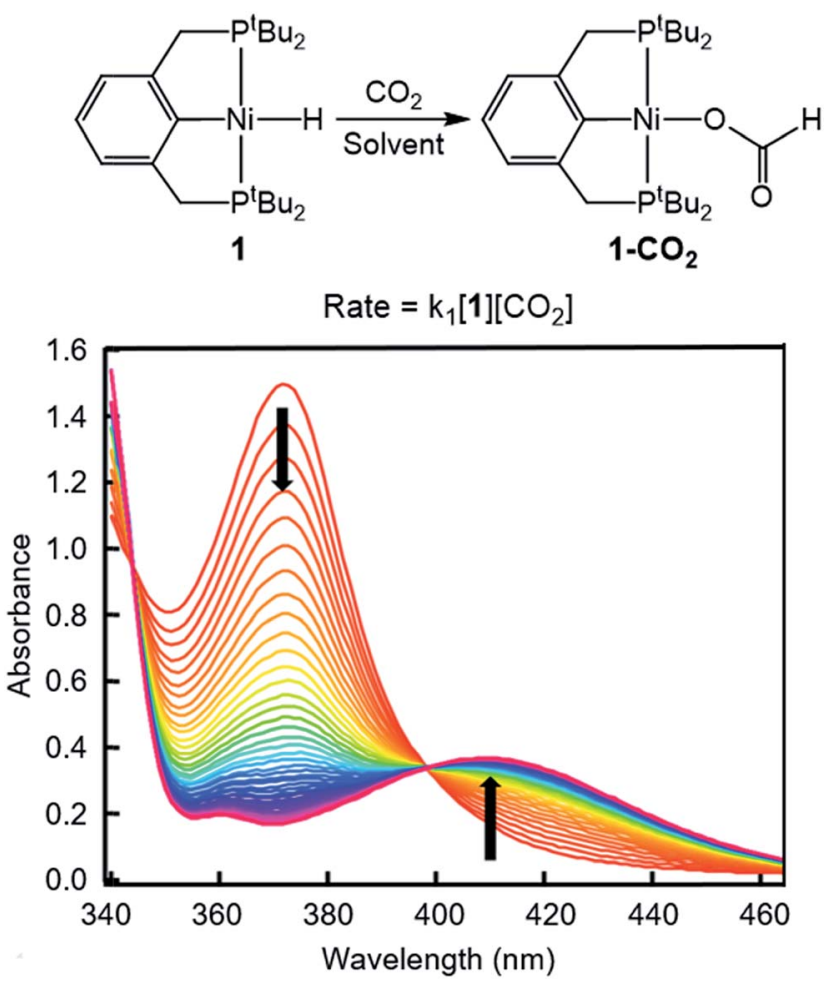

Fig. 1 Representative stopped-flow data for $\mathrm{CO}_{2}$ insertion into 1 . Reaction conditions: [1] $=0.6 \mathrm{mM},\left[\mathrm{CO}_{2}\right]=45 \mathrm{mM}$, benzene, room temperature.

a UV-Vis detector (Fig. 1). This allowed for the measurements of rates on a millisecond timescale at room temperature. Specifically, the reaction was followed spectroscopically from 340 to $560 \mathrm{~nm}$ using a $\geq 20$-fold excess of $\mathrm{CO}_{2}$. Globally fitting the data as a single exponential indicated that the reaction is first order in [1]. Subsequent experiments at different concentrations of $\mathrm{CO}_{2}$ showed that the reaction is also first-order in $\left[\mathrm{CO}_{2}\right]$ (see $\mathrm{ESI} \dagger)$, indicating that the overall rate law is $k_{1}[\mathbf{1}]\left[\mathrm{CO}_{2}\right]$.

Using this methodology, we were able to determine $k_{1}$ under a range of conditions (Table 1). For $\mathrm{CO}_{2}$ insertion into 1, there is excellent agreement between the experimental and computational activation parameters. ${ }^{5 a}$ As shown in Table $1, \mathrm{CO}_{2}$ insertion into 1 exhibits a small solvent effect. The rate of insertion increases by a factor of 32 between THF and MeCN (Table 1, entries 1a and 8). Analysis of the measured rate constants for insertion into $\mathbf{1}$ in a variety of solvents indicates that there is a poor correlation between the solvent dielectric constant and the rate of insertion (Fig. S23 in ESI $\dagger$ ). The observed order of THF $<$ benzene $=$ dioxane $<$ acetone $<1,2-\mathrm{DCE}=\mathrm{DMI}=$ pyridine $<$ MeCN is instead predicted by increasing acceptor number (AN), a measure of the Lewis acidity of the solvent (Fig. 2). ${ }^{11}$ Both Konno et al. and Huang et al. have also demonstrated that there is relationship between the rate of $\mathrm{CO}_{2}$ insertion into a metal hydride and the solvent $\mathrm{AN}$, but for significantly higher polarity solvents. ${ }^{\boldsymbol{b}, \boldsymbol{e}}$ Although there is a solvent effect for $\mathrm{CO}_{2}$ insertion into 1 , the mechanism of insertion likely does not change as a function of solvent, as supported by the consistent activation parameters (Table 1, 
Table 1 Effect of solvent and LAs on the rate of $\mathrm{CO}_{2}$ insertion into 1

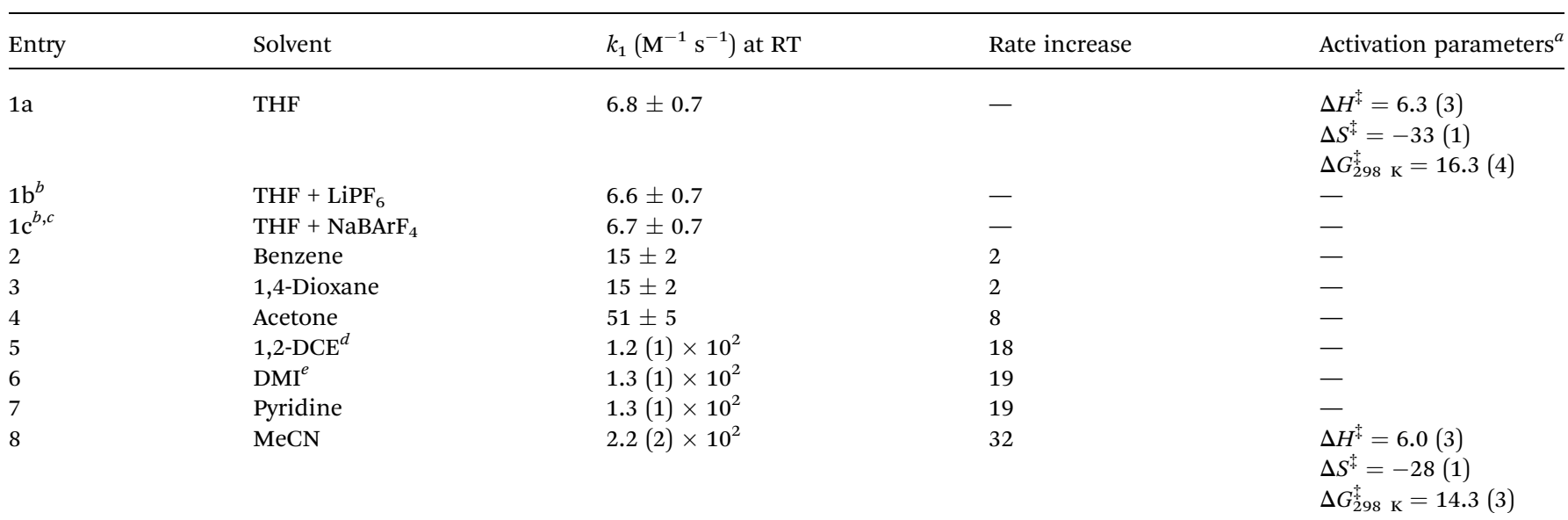

${ }^{a} \Delta H^{*}$ and $\Delta G^{\ddagger}$ in $\mathrm{kcal} \mathrm{mol}^{-1}$ and $\Delta S^{\ddagger}$ in cal $\mathrm{mol}^{-1} \mathrm{~K}^{-1} \cdot{ }^{b}[\mathrm{LA}]=6.0 \mathrm{mM}$ (20 equivalents with respect to 1 ). ${ }^{c} \mathrm{NaBArF}_{4}=\mathrm{sodium}$ tetrakis[3,5bis(trifluoromethyl)phenyl]borate. ${ }^{d} 1,2$-DCE $=1,2$-dichloroethane. ${ }^{e}$ DMI $=1,3$-dimethyl-2-imidazolidinone.

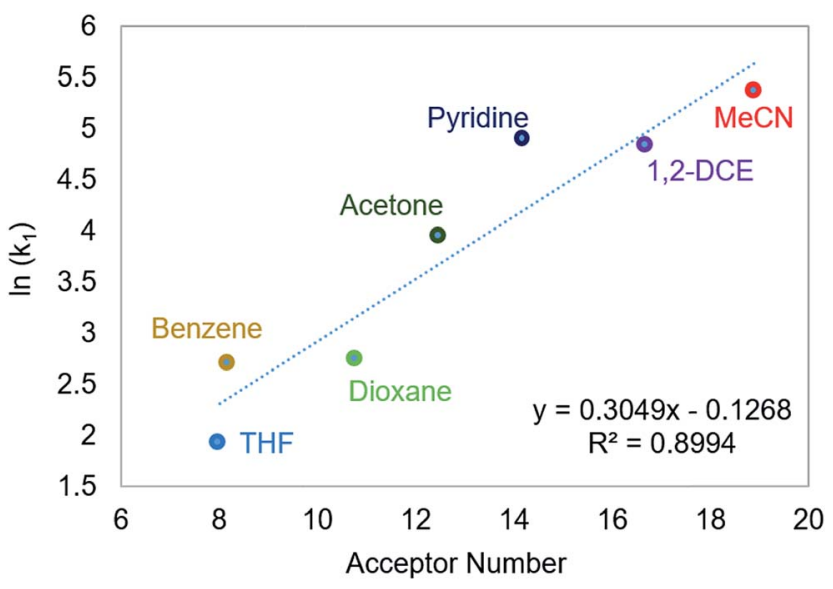

Fig. 2 Relationship between the second-order rate constant $k_{1}$ for $\mathrm{CO}_{2}$ insertion into 1 in various solvents and solvent AN. ${ }^{11}$

entries 1a and 8) and the similar isotope effects in THF and MeCN. Specifically, kinetic studies with $\left({ }^{t \mathrm{Bu}} \mathrm{PCP}\right) \mathrm{NiD}$ revealed inverse isotope effects of $0.61 \pm 0.15 \mathrm{in}$ THF and $0.79 \pm 0.18$ in MeCN (see ESI $\dagger$ ).

Previous studies on catalytic $\mathrm{CO}_{2}$ hydrogenation and formic acid dehydrogenation have demonstrated that LA co-catalysts can dramatically increase both turnover number and turnover frequency. ${ }^{\mathbf{1 f , 2 i , 4 c , 9}}$ This improved catalytic performance was proposed to result from a LA-assisted stabilization of charge in the rate-determining TS of the $\mathrm{CO}_{2}$ insertion (or the microscopic reverse decarboxylation) step. ${ }^{4 c, \boldsymbol{d}}$ Specifically, in these likely outersphere systems, it was suggested that the LA stabilizes the incipient negative charge on the carboxylate group in the rate-determining TS (Fig. 3a), as has been suggested in other systems. ${ }^{7 a, b}$ To probe the relevance of this hypothesis to an innersphere system, we measured the kinetics of $\mathrm{CO}_{2}$ insertion into 1 in the presence of LAs (Table 1, entries 1a-1c). There is no LA effect for this reaction (see Table S $3 \uparrow$ for further information), as the addition of excess (a)

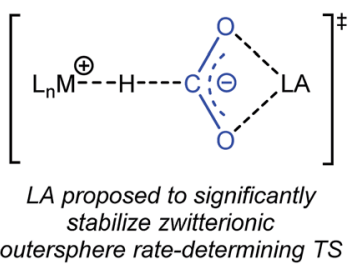

(b)

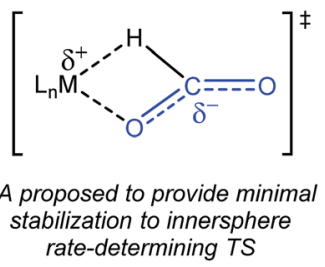

Fig. 3 (a) Proposed stabilization of the zwitterionic outersphere ratedetermining TS in the presence of a LA. (b) Proposed structure of the innersphere rate-determining TS.

$\mathrm{LiPF}_{6}$ or $\mathrm{NaBArF}_{4}$ does not change the rate of insertion. Analyzing the charge separation in the postulated ratedetermining $\mathrm{TS}$ for an innersphere $\mathrm{CO}_{2}$ insertion allows us to rationalize this observation (Fig. 3b). In this case, there is proposed to be only a small amount of charge separation in the rate-determining TS, meaning that the LA can only provide minimal stabilization. This interpretation of our experimental finding suggests a more general conclusion that the rate of $\mathrm{CO}_{2}$ insertion (or decarboxylation) reactions that proceed via an innersphere pathway will not be enhanced by the addition of LAs.

\section{Steric and electronic ligand effect for innersphere $\mathrm{CO}_{2}$ insertion}

Although the insertion of $\mathrm{CO}_{2}$ into 1 exhibits no rate enhancement from LAs and only a small solvent effect, altering the steric and electronic properties of the ancillary ligand may lead to larger changes in the reaction rate. Additionally, to date, systematic studies of the effects of modifying the ancillary ligand on the rate of $\mathrm{CO}_{2}$ insertion in transition metal hydrides are rare, ${ }^{6 a}$ and therefore, it is difficult to rationally promote or inhibit the reaction by changing the supporting ligand. In order to determine how changing the steric properties of the ancillary ligand influences the rate of $\mathrm{CO}_{2}$ insertion, we synthesized $\left({ }^{\mathrm{Cy}} \mathrm{PCP}\right) \mathrm{NiH}\left({ }^{\mathrm{Cy}} \mathrm{PCP}=2,6-\mathrm{C}_{6} \mathrm{H}_{3}\left(\mathrm{CH}_{2} \mathrm{PCy}_{2}\right)_{2}\right)(2)$ and $\left({ }^{\mathrm{iPr}} \mathrm{PCP}\right) \mathrm{NiH}$ 
Table 2 Effect of the phosphine substituents on the rate of $\mathrm{CO}_{2}$ insertion into $\left({ }^{\mathrm{R}} \mathrm{PCP}\right) \mathrm{NiH}$

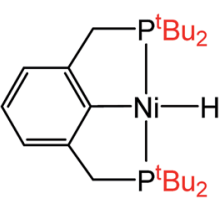

1

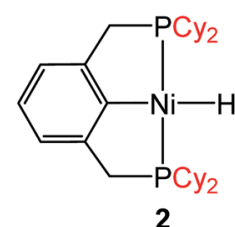

2

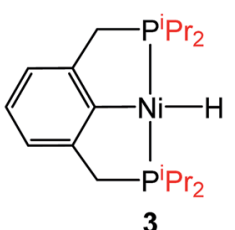

3

\begin{tabular}{lllll}
\hline Entry & $\left({ }^{\mathrm{R}} \mathrm{PCP}\right) \mathrm{NiH}$ & $k_{1}\left(\mathrm{M}^{-1} \mathrm{~s}^{-1}\right)$ at $298 \mathrm{~K}$ in THF & Rate increase & Calculated \% $V_{\text {Bur }}{ }^{a}$ \\
\hline 1 & $\mathbf{1}$ & $6.8 \pm 0.7$ & - & 86.0 \\
2 & 2 & $3.4(3) \times 10^{3}$ & 500 & 79.4 \\
3 & 3 & $4.4(4) \times 10^{3}$ & 647 & 79.9
\end{tabular}

${ }^{a}$ SambVca parameters: 3.5 A sphere radius with Ni atom defined as center, bond radii scaled by $1.17, \mathrm{H}$ atoms included in calculation. ${ }^{12}$

$\left({ }^{\mathrm{PPr}} \mathrm{PCP}=2,6-\mathrm{C}_{6} \mathrm{H}_{3}\left(\mathrm{CH}_{2} \mathrm{P}^{\mathrm{i}} \mathrm{Pr}_{2}\right)_{2}\right)$ (3) using literature methods. ${ }^{\mathbf{1 0}}$ Under $1 \mathrm{~atm} \mathrm{CO}_{2}, 2$ and 3 cleanly generate $\left({ }^{\mathrm{Cy}} \mathrm{PCP}\right) \mathrm{Ni}\{\mathrm{OC}(\mathrm{O}) \mathrm{H}\}$ (2- $\left.\mathrm{CO}_{2}\right)$ and $\left({ }^{\mathrm{iPr}} \mathrm{PCP}\right) \mathrm{Ni}\{\mathrm{OC}(\mathrm{O}) \mathrm{H}\} \quad\left(3-\mathrm{CO}_{2}\right)$, respectively. ${ }^{5 b}$ The kinetics of these reactions were measured and directly compared to those obtained for 1. As shown in Table 2, changing the tert-butyl substituents in $\mathbf{1}$ to cyclohexyl or isopropyl groups led to a drastic enhancement of the reaction rate (500- and 647-fold, respectively). This substantial increase in the rate of $\mathrm{CO}_{2}$ insertion is primarily attributed to the decreased steric congestion around the $\mathrm{Ni}-\mathrm{H}$ bond in $\mathbf{2}$ and $\mathbf{3}$ as compared to 1 . As a quantitative measure of the steric properties of the pincer ligands, the Salerno molecular buried volume calculation (SambVca) was used to calculate the percent buried volume (\% $V_{\text {Bur }}$ ) of these nickel hydrides, ${ }^{12}$ based on their previously reported crystal structures. ${ }^{10,13}$ The calculated values are given in Table 2, and topographic maps illustrating the steric congestion in a qualitative manner are shown in Fig. 4. We propose that the significantly increased steric congestion around the $\mathrm{Ni}-\mathrm{H}$ bond in $\mathbf{1}$ - as evidenced by the larger $\% V_{\mathrm{Bur}}-$ makes it more difficult for $\mathrm{CO}_{2}$ to approach the metal center and insert into the metal hydride bond, resulting in a much lower rate constant than that measured for $\mathbf{2}$ and $\mathbf{3}$.

The large ligand effect outlined above does, however, raise the following question: Is the small magnitude of the solvent effect as well as the lack of a LA effect observed for $\mathrm{CO}_{2}$ insertion into 1 simply a result of increased steric congestion around the reaction center? To address this question, the kinetics of $\mathrm{CO}_{2}$ insertion into 2 were measured in three different solvents and in the presence of LAs (Table 3). The rate of $\mathrm{CO}_{2}$ insertion into 2 does not increase in the presence of a LA (entries 1a-1c). This indicates that the lack of a LA effect seen with $\mathbf{1}$ is, in fact, not an effect of increased steric congestion, but likely a function of a shared characteristic of the reaction pathways for 1 and 2. As the insertion of $\mathrm{CO}_{2}$ into 2 is also proposed to proceed via an innersphere rate-determining TS, this result further supports our proposal that this TS does not involve a significant build-up of charge and, thus, is not stabilized by the addition of a LA even when the reaction center is less sterically crowded. Similarly, the solvent effect observed for $\mathrm{CO}_{2}$ insertion into 2 is on the same order of magnitude as that measured for insertion into $\mathbf{1}$, again suggesting that there are strong mechanistic similarities between $\mathrm{CO}_{2}$ insertion into these two complexes despite their steric differences.

In the proposed innersphere rate-determining $\mathrm{TS}$ for $\mathrm{CO}_{2}$ insertion, there is expected to be a small partial positive charge residing on the metal center (Fig. 3b). This suggests that increased electron density on the metal center may increase the rate of insertion by stabilizing the rate-determining TS, while decreased electron density may slow down the rate. To test this hypothesis, two novel substituted nickel hydrides were prepared - one with an electron-donating methoxy substituent and one with an electron-withdrawing iodo substituent in

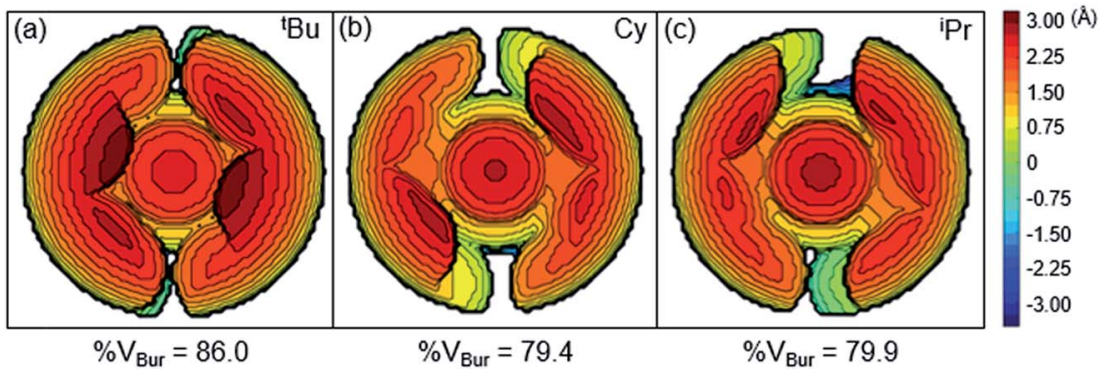

Fig. 4 Topographic steric maps of (a) ( $\left.{ }^{\mathrm{t} B u} \mathrm{PCP}\right) \mathrm{NiH}(1)$, (b) ( $\left.{ }^{\mathrm{C} y} \mathrm{PCP}\right) \mathrm{NiH}(2)$, and (c) ( $\left.{ }^{\mathrm{Pr} P} \mathrm{PCP}\right) \mathrm{NiH}(3)$ as viewed down the $\mathrm{H}-\mathrm{Ni}$ bond towards the plane defined by $\mathrm{P}-\mathrm{Ni}-\mathrm{P} .^{12}$ 
Table 3 Effect of solvent and LAs on the rate of $\mathrm{CO}_{2}$ insertion into 2

\begin{tabular}{|c|c|c|c|c|}
\hline Entry & Solvent & $k_{1}\left(\mathrm{M}^{-1} \mathrm{~s}^{-1}\right)$ at $273 \mathrm{~K}$ & Rate increase & Activation parameters ${ }^{a}$ \\
\hline $1 \mathrm{a}$ & THF & $1.8(2) \times 10^{3}$ & - & $\begin{array}{l}\Delta H^{\dagger}=4.4(3) \\
\Delta S^{\ddagger}=-28(1) \\
\Delta G_{298 \mathrm{~K}}^{\ddagger}=12.6(4)\end{array}$ \\
\hline $1 \mathrm{~b}^{b}$ & $\mathrm{THF}+\mathrm{LiPF}_{6}$ & $1.9(2) \times 10^{3}$ & - & - \\
\hline $1 c^{b}$ & $\mathrm{THF}+\mathrm{NaBArF}_{4}$ & $1.9(2) \times 10^{3}$ & - & - \\
\hline 2 & Benzene & $3.7(4) \times 10^{3}$ & 2 & $\begin{array}{l}\Delta H^{*}=3.0(3) \\
\Delta S^{*}=-31(1) \\
\Delta G_{298 \mathrm{~K}}^{\dagger}=12.3(3)\end{array}$ \\
\hline 3 & Pyridine & $7.9(8) \times 10^{3}$ & 4 & $\begin{array}{l}\Delta H^{*}=4.7(4) \\
\Delta S^{\ddagger}=-23(3) \\
\Delta G_{298 \mathrm{~K}}^{\ddagger}=11.6\end{array}$ \\
\hline
\end{tabular}

the para position of the ancillary ligand. The complexes

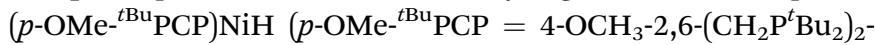

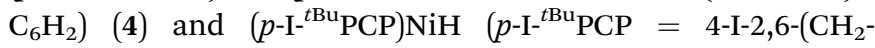
$\left.\mathrm{P}^{t} \mathrm{Bu}_{2}\right)_{2} \mathrm{C}_{6} \mathrm{H}_{2}$ ) (5) were synthesized. Scheme 2 outlines the preparation of the substituted nickel chloride precursors, which is based on previous literature methods. ${ }^{10,14}$ Complex 4 was then prepared from the corresponding nickel chloride using the same procedure as for $\mathbf{1}$ (Scheme $3 \mathrm{a}) .^{\mathbf{1 0}}$ To access 5 , however, a different synthetic route was required (Scheme $3 \mathrm{~b}$ ), due to the tendency of the iodide on the ligand to react with nucleophilic hydride sources such as $\mathrm{NaBH}_{4}$. Initially, a nickel acetate complex was synthesized from $\left(p-\mathrm{I}^{t}{ }^{t \mathrm{Bu}} \mathrm{PCP}\right) \mathrm{NiCl}$ using silver acetate to selectively abstract the chloride. Then pinacolborane (HBPin) was utilized as a transmetalling agent to substitute the acetate for a hydride while still maintaining the iodo substituent in the ligand backbone.

Complexes 4 and 5 both react with 1 atm $\mathrm{CO}_{2}$ to cleanly form $\left(p-\mathrm{OMe}^{t \mathrm{Bu}} \mathrm{PCP}\right) \mathrm{Ni}\{\mathrm{OC}(\mathrm{O}) \mathrm{H}\}\left(\mathbf{4}-\mathrm{CO}_{2}\right)$ and $\left(p-\mathrm{I}-{ }^{t \mathrm{Bu}} \mathrm{PCP}\right) \mathrm{Ni}\{\mathrm{OC}(\mathrm{O}) \mathrm{H}\}$ $\left(5-\mathbf{C O}_{2}\right)$, respectively. The kinetics of these insertions were measured and directly compared to those obtained for $\mathbf{1}$ (Table 4). The incorporation of an electron-donating methoxy group in the para position of the ligand scaffold in 4 resulted in an almost doubling of the reaction rate as compared to the unsubstituted ligand. In contrast, the incorporation of an electron-withdrawing iodo group in $\mathbf{5}$ led to a 4 -fold decrease in the reaction rate, again compared to the unsubstituted ligand. Given the larger magnitude of the Hammett $\sigma_{\mathrm{p}}{ }^{+}$parameter for the methoxy substituent (Table 4), it is rather surprising that the iodo substituent exhibits a more pronounced influence on the reaction rate. Our trends are in agreement with those elucidated for $\mathrm{CO}_{2}$ insertion into $f a c$ - $\mathrm{Re}\left(4,4^{\prime}-\mathrm{X}_{2}-2,2^{\prime}\right.$-bipy $)(\mathrm{CO})_{3} \mathrm{H}(\mathrm{X}=\mathrm{H}, \mathrm{Cl}$,
$\mathrm{Me},{ }^{t} \mathrm{Bu}$, or OMe; bipy = bipyridine), which is the only other quantitative study exploring ligand effects on $\mathrm{CO}_{2}$ insertion into transition metal hydrides. ${ }^{6 \boldsymbol{a}}$ The electronic effect observed here supports our mechanism-based hypothesis and provides guidance on how to modify ancillary ligands to influence the rate of $\mathrm{CO}_{2}$ insertion.

\section{Solvent and Lewis acid effect for outersphere $\mathrm{CO}_{2}$ insertion}

To directly compare inner- and outersphere $\mathrm{CO}_{2}$ insertions, our initial goal was to perform the analogous solvent, LA, and ligand effect experiments with a metal hydride proposed to insert $\mathrm{CO}_{2}$ via an outersphere rate-determining TS. However, due to difficulties finding a suitable system that allowed for ligand effects to be readily probed, our studies with an outersphere system were limited to measuring a solvent and LA effect. Our model complex was the pincer-supported iridium trihydride $\left({ }^{\mathrm{iPr}} \mathrm{PN}^{\mathrm{H}} \mathrm{P}\right) \mathrm{IrH}_{3}\left({ }^{\mathrm{iPr}} \mathrm{PN}^{\mathrm{H}} \mathrm{P}=\mathrm{HN}\left\{\mathrm{CH}_{2} \mathrm{CH}_{2}\left(\mathrm{P}^{\mathrm{i}} \mathrm{Pr}_{2}\right)\right\}_{2}\right)$ (6), which was synthesized using literature methods. ${ }^{15}$ Previous calculations on 6 suggest that $\mathrm{CO}_{2}$ insertion proceeds via an outersphere rate-determining TS. ${ }^{2 b}$ The kinetics of $\mathrm{CO}_{2}$ insertion into 6 to form $\left({ }^{\mathrm{iPr}} \mathrm{PN}^{\mathrm{H}} \mathrm{P}\right) \operatorname{Ir}(\mathrm{H})_{2}\{\mathrm{OC}(\mathrm{O}) \mathrm{H}\} \quad\left(6-\mathbf{C O}_{2}\right)$ were also measured using a rapid mixing stopped-flow instrument with a UV-Vis detector (Fig. 5). The reaction was followed spectroscopically from 325 to $700 \mathrm{~nm}$, and rates were measured under non pseudo-first order $\left[\mathrm{CO}_{2}\right]$ conditions to slow the reaction to observable timescales. The positive linear relationship between the measured initial rate and the concentration of $\mathrm{CO}_{2}$ at various $\left[\mathrm{CO}_{2}\right]$ confirms that the reaction is first-order in $\left[\mathrm{CO}_{2}\right]$ (see Fig. S21 in ESI $\dagger$ ). The elementary second-order rate constant $k_{1}$ for the insertion of $\mathrm{CO}_{2}$ into 6 (Tables 5 and 6) was

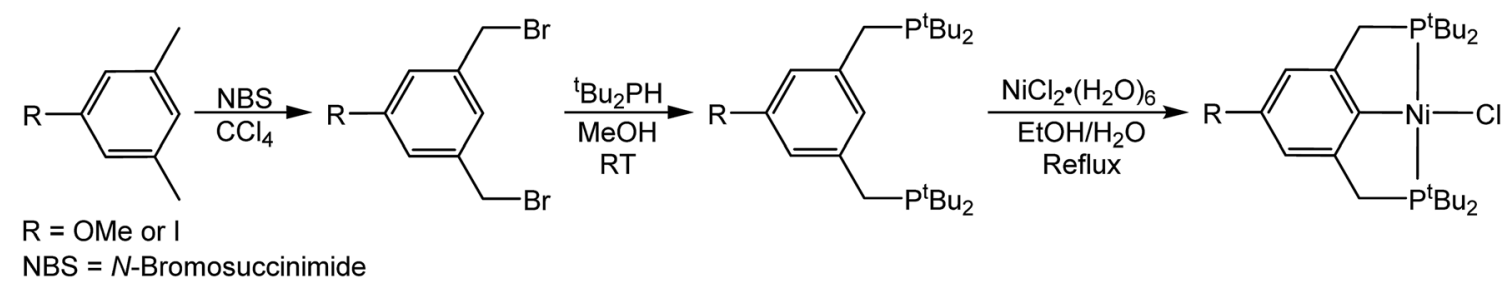

Scheme 2 Synthesis of $\left(p-R_{-}{ }^{t B u} P C P\right) N i C l$ where $\mathrm{R}=$ OMe or I. 
(a)<smiles>CCCCN1Cc2cc(OC)cc3c2N1[Pb](Cl)C3</smiles>

(b)

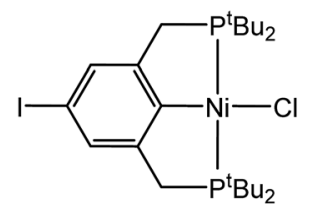

$\stackrel{\mathrm{AgOC}(\mathrm{O}) \mathrm{CH}_{3}}{\longrightarrow}$ THF

directly determined by globally fitting the data as a bimolecular reaction with rate law $k_{1}[6]\left[\mathrm{CO}_{2}\right]$. As with $\mathrm{CO}_{2}$ insertion into $\mathbf{1}$, there is excellent agreement between the experimental and computational activation parameters for $\mathrm{CO}_{2}$ insertion into 6 . $^{2 b}$

$\mathrm{CO}_{2}$ insertion into 6 exhibits a small solvent effect on the same order of magnitude as that observed for $\mathrm{CO}_{2}$ insertion into 1. The rate of insertion increases by a factor of 29 between diethyl ether (Table 5, entry 1 ) and benzene (Table 5, entry 7 ). Unfortunately, 6 is not stable in more polar solvents, and the rate of $\mathrm{CO}_{2}$ insertion in these solvents, consequently, could not be measured. In contrast to the insertion of $\mathrm{CO}_{2}$ into 1 , there is no correlation between the solvent dielectric constant or AN and the rate of insertion for all seven solvents tested (see Fig. S24 and $\mathrm{S} 25$ in $\mathrm{ESI} \dagger$ ). The rate of $\mathrm{CO}_{2}$ insertion into 6 does, however, strongly correlate with the solvent AN when the analysis is narrowed to only the five ethereal solvents used (Fig. 6). The unusual kinetics observed in $n$-hexane and benzene - highlighted by the lower enthalpy for $n$-hexane as well as the substantially higher enthalpy and less negative entropy of activation for benzene compared to the ethereal solvents - are not fully understood at the time. Regardless, our results indicate that there is not always correlation between $\mathrm{AN}$ and the rate of $\mathrm{CO}_{2}$ insertion. Further work with more complexes is required to understand the generality of this relationship.

To probe the proposition that the presence of a LA increases the rate of an outersphere $\mathrm{CO}_{2}$ insertion by stabilizing the incipient negative charge on the carboxylate group in the ratedetermining TS (Fig. 3a), ${ }^{4 c, d}$ we measured the kinetics of $\mathrm{CO}_{2}$

Table 4 Effect of the para-substituent on the rate of $\mathrm{CO}_{2}$ insertion into $\left(p-\mathrm{R}^{-{ }^{\mathrm{B} u}}{ }^{\mathrm{PCP}}\right) \mathrm{NiH}$

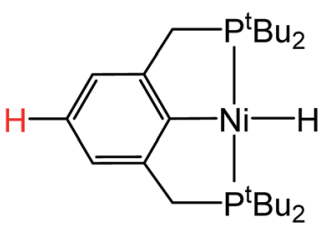

1

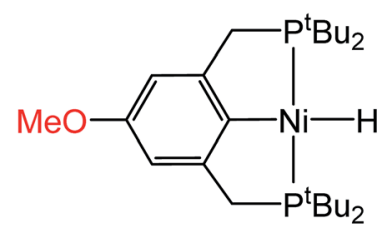

4

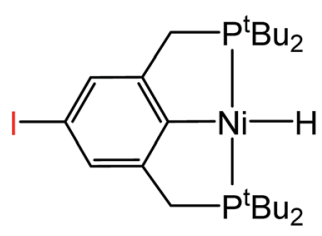

5

\begin{tabular}{llccc}
\hline Entry & $\left(p-\mathrm{R}^{t \mathrm{Bu}} \mathrm{PCP}\right) \mathrm{NiH}$ & $k_{1}\left(\mathrm{M}^{-1} \mathrm{~s}^{-1}\right)$ at RT in THF & Rate increase \\
\hline 1 & $\mathbf{5}$ & $1.6 \pm 0.2$ & - & $\sigma_{\mathrm{p}}^{+a}$ \\
2 & $\mathbf{1}$ & $6.8 \pm 0.7$ & 4 & +0.13 \\
3 & $\mathbf{4}$ & $11.7 \pm 1$ & - & 7
\end{tabular}

${ }^{a}$ C. D. Ritchie and W. F. Sager, Prog. Phys. Org. Chem., 1964, 2, 323. 

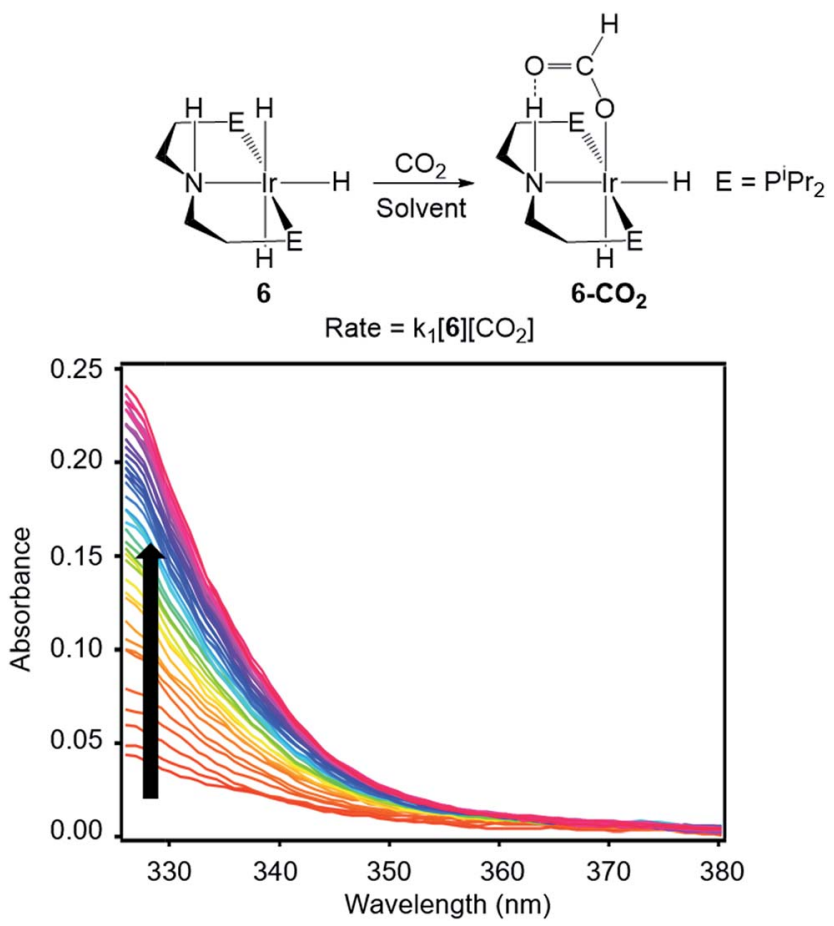

Fig. 5 Representative stopped-flow data for $\mathrm{CO}_{2}$ insertion into 6 . Reaction conditions: [6] $=2 \mathrm{mM},\left[\mathrm{CO}_{2}\right]=11 \mathrm{mM}, \mathrm{THF}, 243 \mathrm{~K}$.

insertion into 6 in the presence of 10 different LAs. In contrast to the insertion of $\mathrm{CO}_{2}$ into 1 , the addition of LAs ( $\geq 10$-fold excess with respect to 6) results in a substantial enhancement in the reaction rate (Table 6, entries 1 and $3-12$ ). When the concentration of $\mathrm{LiPF}_{6}$ was varied, a first-order dependence was observed (Fig. 7). This indicates that in the presence of LAs, there is an approximate third order rate law for $\mathrm{CO}_{2}$ insertion $k_{1}[6]\left[\mathrm{CO}_{2}\right][\mathrm{LA}] .{ }^{16}$ Several control experiments were performed to confirm that the observed increase in rate was due to a LA effect. To explore the effect of increasing the ionic strength of the solution without adding a $\mathrm{LA}$, the rate of $\mathrm{CO}_{2}$ insertion into 6 was measured in the presence of $\left({ }^{n} \mathrm{Bu}\right)_{4} \mathrm{NPF}_{6}$ (Table 6 , entry 2). The rate of product formation for $\mathrm{CO}_{2}$ insertion into 6 increases by only a factor of 3 in the presence of 20 equivalents of $\left({ }^{n} \mathrm{Bu}\right)_{4} \mathrm{NPF}_{6}$ (see Table $\mathrm{S} 4$ in ESI $\dagger$ ), indicating that while an increase in ionic strength may play a small role in the rate enhancement, the presence of the LA is a dominant factor. Furthermore, the activation enthalpy for $\mathrm{CO}_{2}$ insertion in the presence of $\left({ }^{n} \mathrm{Bu}\right)_{4} \mathrm{NPF}_{6}$ is similar to that measured with no additive, suggesting that $\left({ }^{n} \mathrm{Bu}\right)_{4} \mathrm{NPF}_{6}$ does not change the mechanism of insertion (Table 6 , entries 1 and 2). The activation enthalpy for $\mathrm{CO}_{2}$ insertion in the presence of $\mathrm{LiPF}_{6}$ is, however, markedly lower than that obtained with no additive (Table 6, entries 1 and 7), suggesting that the LA directly interacts with the metal complex in the rate-determining TS. $^{17}$ Significant changes in the activation enthalpies were also observed with other LAs.

Of the ten LAs tested, $\mathrm{KB}\left(\mathrm{C}_{6} \mathrm{~F}_{5}\right)_{4}$ and $\mathrm{NaBArF}_{4}$ gave the most significant rate enhancements. In fact, extrapolation of our data suggests that with just 20 equivalents of $\mathrm{NaBArF}_{4}$, a 100fold rate enhancement would be obtained. Furthermore, given the first order dependence on [LA], this enhancement could in principle be increased even more dramatically by further increasing [LA]. Our data indicate that there is significant variation in the observed rate enhancements within a series of anions with the same cation (e.g. NaOTf, $\mathrm{NaNTf}_{2}, \mathrm{NaBPh}_{4}$, and $\mathrm{NaBArF}_{4}$ ). We suggest that this is related

Table 5 Effect of solvent on the rate of $\mathrm{CO}_{2}$ insertion into 6

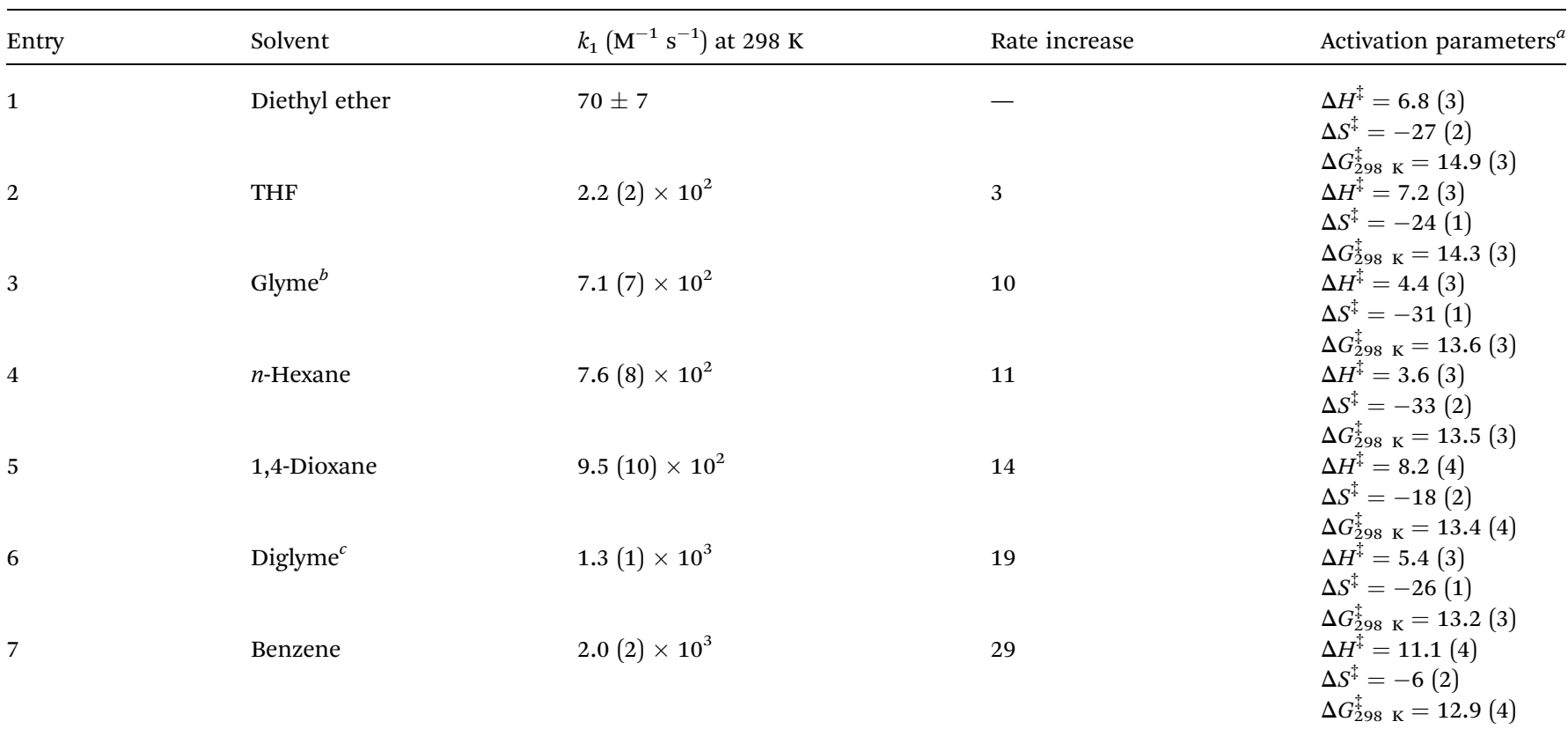

${ }^{a} \Delta H^{\ddagger}$ and $\Delta G^{\ddagger}$ in $\mathrm{kcal} \mathrm{mol}^{-1}$ and $\Delta S^{\ddagger}$ in cal $\mathrm{mol}^{-1} \mathrm{~K}^{-1} \cdot{ }^{b}$ Glyme $=1,2$-dimethoxyethane. ${ }^{c}$ Diglyme $=$ diethylene glycol dimethyl ether. 
Table 6 Effect of additives on the rate of $\mathrm{CO}_{2}$ insertion into 6 in THF

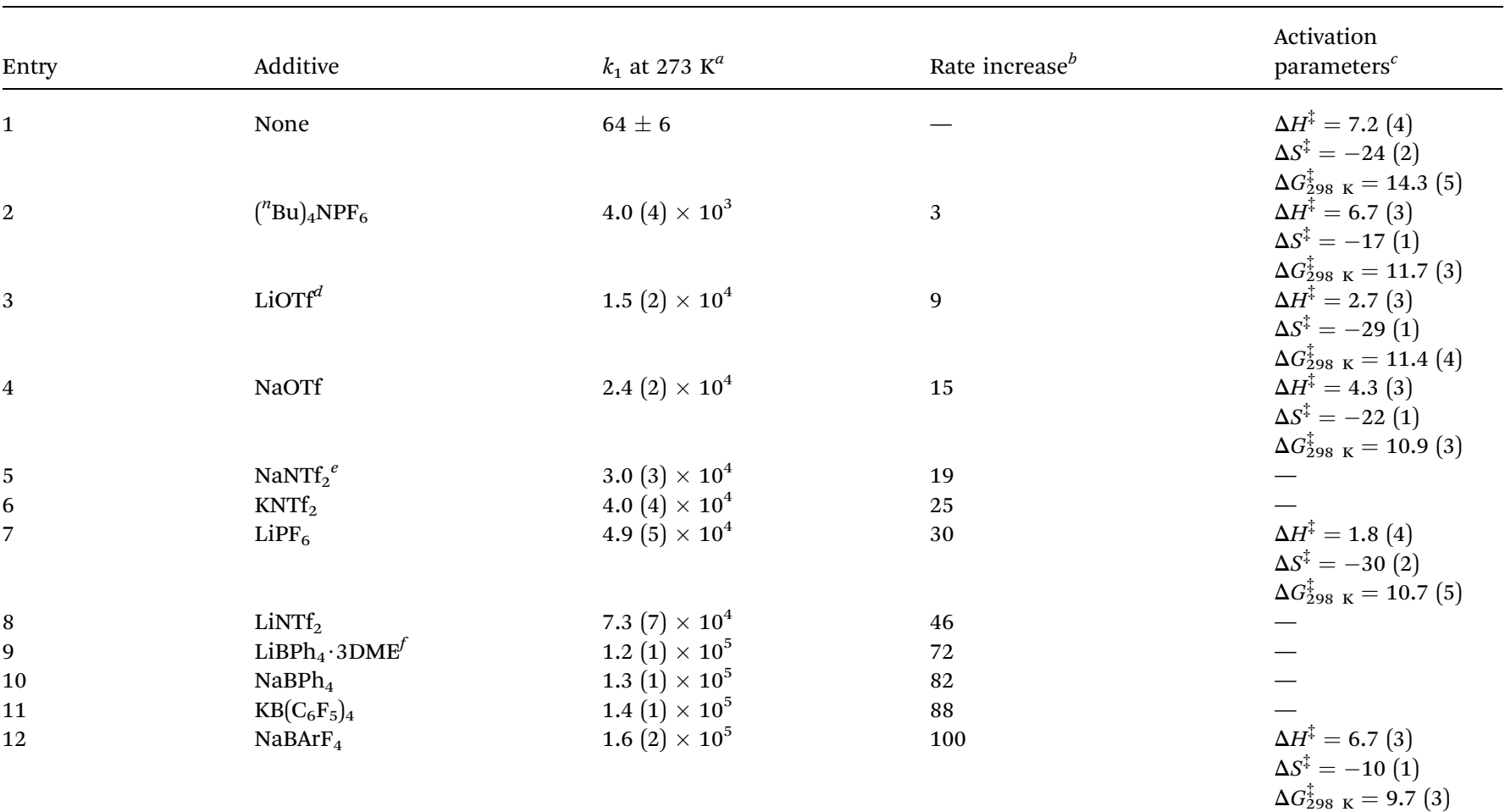

${ }^{a}$ Entry 1 follows the second order rate law $k_{1}[6]\left[\mathrm{CO}_{2}\right]$, where $k_{1}$ is in $\mathrm{M}^{-1} \mathrm{~s}^{-1}$; entries 2-12 are assumed to follow the third order rate law $k_{1}[6]\left[\mathrm{CO}_{2}\right]$ [LA], where $k_{1}$ is in $\mathrm{M}^{-2} \mathrm{~s}^{-1} .{ }^{b}$ The rate increase is based on the calculated rate of product formation $\left(\mathrm{M} \mathrm{s}^{-1}\right)$ in the presence of 20 equivalents of LA (relative to [6]). This allows for the comparison of rates independent of overall reaction order. Due to the poor solubility of the LA, entries 9-12 were run with only 10 equivalents of LA and extrapolated to 20 equivalents. See ESI for further information. ${ }^{c} \Delta H^{\ddagger}$ and $\Delta G^{\ddagger}$ in kcal mol ${ }^{-1}$ and $\Delta S^{\ddagger}$ in cal $\mathrm{mol}^{-1} \mathrm{~K}^{-1}$. ${ }^{d} \mathrm{OTF}=$ trifluoromethanesulfonate. ${ }^{e} \mathrm{NTf}_{2}=$ bis(trifluoromethane)sulfonamide. ${ }^{f} \mathrm{LiBPh}_{4} \cdot 3 \mathrm{DME}=$ lithium tetraphenylborate tris $(1,2$ dimethoxyethane).

to differences in ion-pairing, i.e. $\mathrm{NaBArF}_{4}$ is more dissociated than NaOTf in THF, resulting in an increased effective concentration of $\mathrm{Na}^{+},{ }^{18}$ as opposed to the anion having an explicit role in the reaction. Ion-pairing effects also potentially complicate direct comparison between cations. For example, the smaller rate enhancement seen with LiOTf as

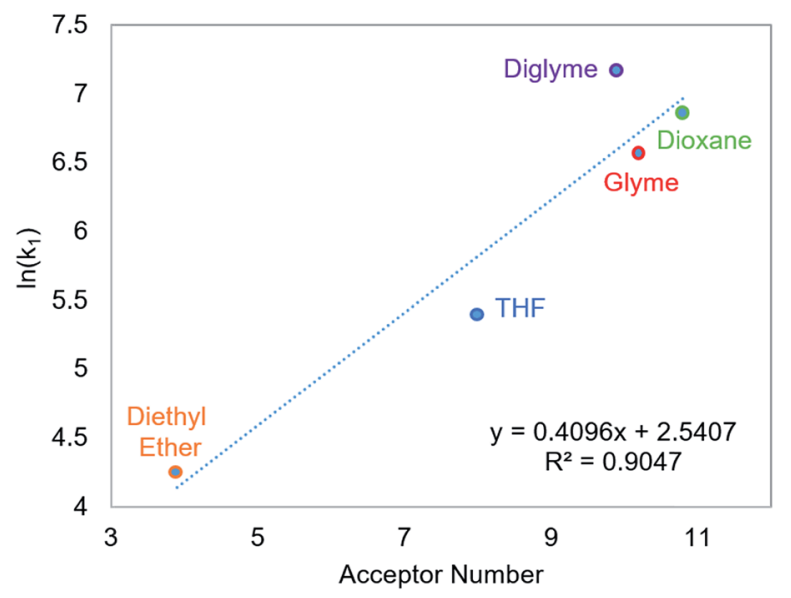

Fig. 6 Relationship between the second-order rate constant $k_{1}$ for $\mathrm{CO}_{2}$ insertion into 6 in ethereal solvents and solvent acceptor number. ${ }^{11}$ compared to NaOTf may be interpreted as LiOTf being less dissociated in THF rather than $\mathrm{Na}^{+}$more effectively stabilizing a transition state than $\mathrm{Li}^{+}$. The results with LAs presented here are the first quantitative demonstration that these additives can directly increase the rate of $\mathrm{CO}_{2}$ insertion into transition metal hydrides.

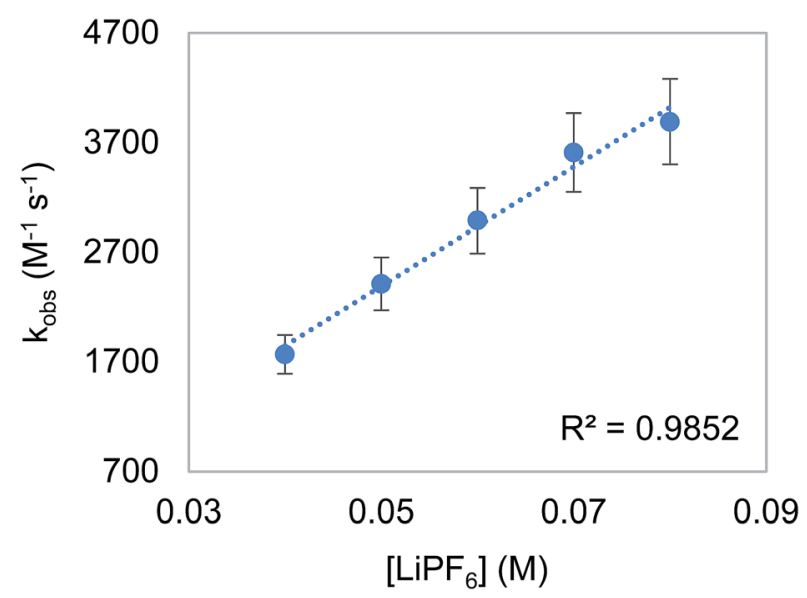

Fig. 7 Plot of observed rate constant $\left(k_{\text {obs }}\right)$ versus $\left[\mathrm{LiPF}_{6}\right]$ for the insertion of $\mathrm{CO}_{2}$ into 6 . Reaction conditions: [6] $=2 \mathrm{mM},\left[\mathrm{CO}_{2}\right]=$ $6.6 \mathrm{mM},\left[\mathrm{LiPF}_{6}\right]=40-80 \mathrm{mM}, \mathrm{THF}, 273 \mathrm{~K}$. 


\section{Conclusions}

In this work, we have used stopped-flow kinetics to systematically probe both inner- and outersphere $\mathrm{CO}_{2}$ insertion reactions. For the innersphere system, we have demonstrated that the rate of $\mathrm{CO}_{2}$ insertion can be significantly changed by modifying the ancillary ligand. Both decreasing the steric congestion around the $\mathrm{M}-\mathrm{H}$ bond and/or increasing the electron density on the metal center by, for example, incorporating an electron-donating substituent result in faster rates of $\mathrm{CO}_{2}$ insertion. Additionally, both inner- and outersphere reactions show similar solvent effects that are loosely correlated with the solvent acceptor number, although the generality of this observation is not clear. Lastly, we have quantitatively shown that the rate of $\mathrm{CO}_{2}$ insertion into 1 and 2, which are proposed to proceed via an innersphere pathway, does not increase in the presence of a LA, whereas the rate of $\mathrm{CO}_{2}$ insertion into 6, proposed to proceed via an outersphere pathway, increases significantly in the presence of a LA. Although the effects of LAs on insertion into metal-element $\sigma$-bonds are well understood for substrates such as $\mathrm{CO},{ }^{19}$ they remain relatively unexplored for $\mathrm{CO}_{2}$. While the effect of $\mathrm{LAs}$ on $\mathrm{CO}_{2}$ insertion into metal-alkyl bonds has been studied, ${ }^{7 a-c}$ the work presented here is the first quantification of these effects for $\mathrm{CO}_{2}$ insertion into metal hydrides. The effects and observations outlined here are rationalized by the proposed charge separation in the rate-determining TS in an inner- $v s$. outersphere insertion. The presence of a LA is expected to provide stabilization for the zwitterionic ratedetermining TS in an outersphere $\mathrm{CO}_{2}$ insertion, resulting in a rate increase. As this TS is not rate-determining in an innersphere insertion, the stabilization provided by the LA does not affect the rate of the reaction. In future work, we will utilize the experimental procedures we have developed here to establish whether these trends relating to LA and solvent effects are general to other metal hydrides that insert $\mathrm{CO}_{2}$. We will also explore how these variables affect the insertion of $\mathrm{CO}_{2}$ into other metalelement $\sigma$-bonds, such as $\mathrm{M}-\mathrm{OH}, \mathrm{M}-\mathrm{NH}_{2}$, and $\mathrm{M}-\mathrm{CH}_{3}$ bonds. It is expected that our current and future results will provide insight into how to optimize catalytic reactions involving $\mathrm{CO}_{2}$ insertion into a metal-element $\sigma$-bonds or the microscopic reverse decarboxylation reaction as elementary steps.

\section{Additional information}

Full compound characterization, experimental procedures, and kinetics data are available via the Internet.

\section{Conflicts of interest}

The authors declare no competing financial interests.

\section{Acknowledgements}

$\mathrm{NH}$ and WHB acknowledge support from the U.S. Department of Energy, Office of Science, Basic Energy Sciences, Catalysis Science Program, under Award DE-SC0018222. NH also acknowledges support from the National Science Foundation through Grant CHE-1150826. JMM was supported as part of the
Argonne-Northwestern Solar Energy Research Center, an Energy Frontier Research Center funded by the U.S. Department of Energy, Office of Science, Basic Energy Sciences, under Award No. DE-SC0001059. The stopped-flow instrument was supported by the U.S. National Institutes of Health award GM050422. We are grateful to Dr David Balcells and Dr Ainara Nova for valuable discussions as well as Matthew Espinosa and Ian Peczak for their synthetic contributions.

\section{References}

1 (a) M. Peters, B. Köhler, W. Kuckshinrichs, W. Leitner, P. Markewitz and T. E. Müller, ChemSusChem, 2011, 4, 1216-1240; (b) M. Cokoja, C. Bruckmeier, B. Rieger, W. A. Herrmann and F. E. Kühn, Angew. Chem., Int. Ed., 2011, 50, 8510-8537; (c) A. M. Appel, J. E. Bercaw, A. B. Bocarsly, H. Dobbek, D. L. DuBois, M. Dupuis, J. G. Ferry, E. Fujita, R. Hille, P. J. A. Kenis, C. A. Kerfeld, R. H. Morris, C. H. F. Peden, A. R. Portis, S. W. Ragsdale, T. B. Rauchfuss, J. N. H. Reek, L. C. Seefeldt, R. K. Thauer and G. L. Waldrop, Chem. Rev., 2013, 113, 6621-6658; (d) W.-H. Wang, Y. Himeda, J. T. Muckerman, G. F. Manbeck and E. Fujita, Chem. Rev., 2015, 115, 12936-12973; (e) J. Klankermayer, S. Wesselbaum, K. Beydoun and W. Leitner, Angew. Chem., Int. Ed., 2016, 55, 7296-7343; (f) W. H. Bernskoetter and N. Hazari, Acc. Chem. Res., 2017, 50, 1049-1058.

2 For leading references see: $(a)$ R. Tanaka, M. Yamashita and K. Nozaki, J. Am. Chem. Soc., 2009, 131, 14168-14169; (b) T. J. Schmeier, G. E. Dobereiner, R. H. Crabtree and N. Hazari, J. Am. Chem. Soc., 2011, 133, 9274-9277; (c) C. A. Huff and M. S. Sanford, J. Am. Chem. Soc., 2011, 133, 18122-18125; (d) R. Langer, Y. Diskin-Posner, G. Leitus, L. J. W. Shimon, Y. Ben-David and D. Milstein, Angew. Chem., Int. Ed., 2011, 50, 9948-9952; (e) C. Ziebart, C. Federsel, P. Anbarasan, R. Jackstell, W. Baumann, A. Spannenberg and M. Beller, J. Am. Chem. Soc., 2012, 134, 20701-20704; $(f)$ J. F. Hull, Y. Himeda, W.-H. Wang, B. Hashiguchi, R. Periana, D. J. Szalda, J. T. Muckerman and E. Fujita, Nat. Chem., 2012, 4, 383-388; $(g)$ M. S. Jeletic, M. T. Mock, A. M. Appel and J. C. Linehan, J. Am. Chem. Soc., 2013, 135, 11533-11536; (h) S. Wesselbaum, V. Moha, M. Meuresch, S. Brosinski, K. M. Thenert, J. Kothe, T. v. Stein, U. Englert, M. Holscher, J. Klankermayer and W. Leitner, Chem. Sci., 2015, 6, 693-704; (i) Y. Zhang, A. D. MacIntosh, J. L. Wong, E. A. Bielinski, P. G. Williard, B. Q. Mercado, N. Hazari and W. H. Bernskoetter, Chem. Sci., 2015, 6, 4291-4299; (j) N. M. Rezayee, C. A. Huff and M. S. Sanford, J. Am. Chem. Soc., 2015, 137, 1028-1031; (k) A. M. Lilio, M. H. Reineke, C. E. Moore, A. L. Rheingold, M. K. Takase and C. P. Kubiak, J. Am. Chem. Soc., 2015, 137, 8251-8260.

3 (a) D. Mellmann, P. Sponholz, H. Junge and M. Beller, Chem. Soc. Rev., 2016, 45, 3954-3988; (b) A. K. Singh, S. Singh and A. Kumar, Catal. Sci. Technol., 2016, 6, 12-40; (c) K. Sordakis, C. Tang, L. K. Vogt, H. Junge, P. J. Dyson, M. Beller and G. Laurenczy, Chem. Rev., 2018, 118, 372-433. 
4 For leading references see: (a) A. Boddien, D. Mellmann, F. Gärtner, R. Jackstell, H. Junge, P. J. Dyson, G. Laurenczy, R. Ludwig and M. Beller, Science, 2011, 333, 1733-1736; (b) T. Zell, B. Butschke, Y. Ben-David and D. Milstein, Chem.Eur. J., 2013, 19, 8068-8072; (c) E. A. Bielinski, P. O. Lagaditis, Y. Zhang, B. Q. Mercado, C. Würtele, W. H. Bernskoetter, N. Hazari and S. Schneider, J. Am. Chem. Soc., 2014, 136, 10234-10237; (d) E. A. Bielinski, M. Förster, Y. Zhang, W. H. Bernskoetter, N. Hazari and M. C. Holthausen, ACS Catal., 2015, 5, 2404-2415; (e) E. Alberico, A. J. J. Lennox, L. K. Vogt, H. Jiao, W. Baumann, H.-J. Drexler, M. Nielsen, A. Spannenberg, M. P. Checinski, H. Junge and M. Beller, J. Am. Chem. Soc., 2016, 138, 14890-14904; $(f)$ J. J. A. Celaje, Z. Lu, E. A. Kedzie, N. J. Terrile, J. N. Lo and T. J. Williams, Nat. Commun., 2016, 7, 11308; $(g)$ M. Andérez-Fernández, L. K. Vogt, S. Fischer, W. Zhou, H. Jiao, M. Garbe, S. Elangovan, K. Junge, H. Junge, R. Ludwig and M. Beller, Angew. Chem., Int. Ed., 2017, 56, 559-562.

5 (a) T. J. Schmeier, N. Hazari, C. D. Incarvito and J. A. Raskatov, Chem. Commun., 2011, 47, 1824-1826; (b) H.-W. Suh, T. J. Schmeier, N. Hazari, R. A. Kemp and M. K. Takase, Organometallics, 2012, 31, 8225-8236; (c) P. Ríos, A. Rodríguez and J. López-Serrano, ACS Catal., 2016, 6, 5715-5723; (d) W. H. Bernskoetter and N. Hazari, Eur. J. Inorg. Chem., 2013, 4032-4041; (e) N. Hazari and J. E. Heimann, Inorg. Chem., 2017, 56, 13655-13678.

6 (a) B. P. Sullivan and T. J. Meyer, Organometallics, 1986, 5, 1500-1502; (b) H. Konno, A. Kobayashi, K. Sakamoto, F. Fagalde, N. E. Katz, H. Saitoh and O. Ishitani, Inorg. Chim. Acta, 2000, 299, 155-163; (c) C. Creutz and M. H. Chou, J. Am. Chem. Soc., 2007, 129, 10108-10109; (d) P. Kang, C. Cheng, Z. Chen, C. K. Schauer, T. J. Meyer and M. Brookhart, J. Am. Chem. Soc., 2012, 134, 5500-5503; (e) J. Huang, J. Chen, H. Gao and L. Chen, Inorg. Chem., 2014, 53, 9570-9580; (f) Q.-Q. Ma, T. Liu, A. Adhikary, J. Zhang, J. A. Krause and H. Guan, Organometallics, 2016, 35, 40774082.

7 For kinetic studies on $\mathrm{CO}_{2}$ insertion into $\mathrm{M}-\mathrm{Me}$ bonds see: (a) D. J. Darensbourg and A. Rokicki, J. Am. Chem. Soc., 1982, 104, 349-350; (b) D. J. Darensbourg and M. Pala, J. Am. Chem. Soc., 1985, 107, 5687-5693; (c) K.-C. Lau, B. J. Petro, S. Bontemps and R. F. Jordan, Organometallics, 2013, 32, 6895-6898; (d) K.-C. Lau and R. F. Jordan, Organometallics, 2016, 35, 3658-3666.

8 For kinetic studies on $\mathrm{CO}_{2}$ insertion into $\mathrm{M}-\mathrm{OH}$ bonds see: (a) D. Huang, O. V. Makhlynets, L. L. Tan, S. C. Lee, E. V. Rybak-Akimova and R. H. Holm, Inorg. Chem., 2011, 50, 10070-10081; (b) D. Huang, O. V. Makhlynets,
L. L. Tan, S. C. Lee, E. V. Rybak-Akimova and R. H. Holm, Proc. Natl. Acad. Sci. U. S. A., 2011, 108, 1222-1227.

9 (a) A. Z. Spentzos, C. L. Barnes and W. H. Bernskoetter, Inorg. Chem., 2016, 55, 8225-8233; (b) F. Bertini, M. Glatz, N. Gorgas, B. Stoger, M. Peruzzini, L. F. Veiros, K. Kirchner and L. Gonsalvi, Chem. Sci., 2017, 8, 5024-5029; (c) S. Siek, D. B. Burks, D. L. Gerlach, G. Liang, J. M. Tesh, C. R. Thompson, F. Qu, J. E. Shankwitz, R. M. Vasquez, N. Chambers, G. J. Szulczewski, D. B. Grotjahn, C. E. Webster and E. T. Papish, Organometallics, 2017, 36, 1091-1106.

10 B. J. Boro, E. N. Duesler, K. I. Goldberg and R. A. Kemp, Inorg. Chem., 2009, 48, 5081-5087.

11 U. Mayer, V. Gutmann and W. Gerger, Monatsh. Chem., 1975, 106, 1235-1257.

12 (a) H. Clavier and S. P. Nolan, Chem. Commun., 2010, 46, 841-861; (b) L. Falivene, R. Credendino, A. Poater, A. Petta, L. Serra, R. Oliva, V. Scarano and L. Cavallo, Organometallics, 2016, 35, 2286-2293.

13 L. M. Martínez-Prieto, C. Melero, D. del Río, P. Palma, J. Cámpora and E. Álvarez, Organometallics, 2012, 31, 14251438.

14 K. Krogh-Jespersen, M. Czerw, K. Zhu, B. Singh, M. Kanzelberger, N. Darji, P. D. Achord, K. B. Renkema and A. S. Goldman, J. Am. Chem. Soc., 2002, 124, 1079710809.

15 Z. E. Clarke, P. T. Maragh, T. P. Dasgupta, D. G. Gusev, A. J. Lough and K. Abdur-Rashid, Organometallics, 2006, 25, 4113-4117.

16 The true rate law in the presence of a LA is $k_{1}[6]\left[\mathrm{CO}_{2}\right][\mathrm{LA}]+$ $k_{2}[6]\left[\mathrm{CO}_{2}\right]$, where the second term equals the rate of insertion in the absence of a LA (Table 6, entry 1 ). The rate can be approximated as $k_{1}[6]\left[\mathrm{CO}_{2}\right][\mathrm{LA}]$, as this term is at least an order of magnitude larger than the second term under our reaction conditions (10-20 equivalents of LA).

17 Although modelling the speciation of alkali metal ions such as $\mathrm{Li}^{+}$or $\mathrm{Na}^{+}$in organic solvents is challenging, DFT calculations are currently being performed to understand the nature of a potential interaction between the LA, metal complex, and $\mathrm{CO}_{2}$ in the rate-determining TS.

18 (a) D. N. Bhattacharyya, C. L. Lee, J. Smid and M. Szwarc, J. Phys. Chem., 1965, 69, 608-611; (b) D. Nicholls, C. Sutphen and M. Szwarc, J. Phys. Chem., 1968, 72, 1021-1027; (c) Y. Marcus and G. Hefter, Chem. Rev., 2006, 106, 4585-4621; (d) K. E. Aldrich, B. S. Billow, D. Holmes, R. D. Bemowski and A. L. Odom, Organometallics, 2017, 36, 1227-1237.

19 S. B. Butts, S. H. Strauss, E. M. Holt, R. E. Stimson, N. W. Alcock and D. F. Shriver, J. Am. Chem. Soc., 1980, 102, 5093-5100. 